\title{
Cultura material e a experiência africana no sudeste oitocentista: cachimbos de escravos em imagens, histórias, estilos e listagens
}

\author{
Camilla Agostini
}

Este trabalho tem como objetivo expor alguns aspectos metodológicos considerados na análise de amostras compostas por cachimbos cerâmicos encontrados em sítios arqueológicos na região sudeste brasileira, em contextos do século XIX, observando algumas estratégias para a utilização de fontes de diferentes naturezas para inferir sobre a produção, circulação e uso dessas peças e possíveis significados a elas atribuídos.

O cruzamento de informações empíricas extraídas de fontes distintas é uma estratégia metodológica tão fértil quanto perigosa no desenvolvimento de estudos interdisciplinares, como alerta Feinman (1997), entre outros autores. ${ }^{1} \mathrm{O}$ autor chama a atenção para a negligência metodológica de arqueólogos ao fazerem uso de fontes documentais e de historiadores com o uso (quando fazem uso) dos vestígios arqueológicos, enfatizando que todo corpo de dados é uma construção do pesquisador, realizada para propósitos específicos e a partir de abordagens específicas. Feinman sugere que fontes de naturezas diferentes devem ser trabalhadas de forma independente, para que as informações extraídas de cada 'corpo de dados' sejam justapostas no final, e não sobrepostas, como forma de atribuir autenticidade ou veracidade às informações extraídas dos dados trabalhados dentro da disciplina original do pesquisador, ou meramente ilustrá-las. ${ }^{2}$

Aqui vale lembrar o conceito de 'metadados' utilizado por Consens (2000) para pensarmos que o cruzamento das informações extraídas de corpos documentais de naturezas distintas pode se dar nos três níveis de análise destacados pelo autor: na coleta dos dados empíricos, na criação dos metadados (realizada de acordo com as estratégias metodológicas e teóricas do pesquisador), e na interpretação dos dados. Sendo o perigo deste cruzamento, tal como alertado por Feinman, a associação das informações neste primeiro nível, de coleta.

Além do problema de se privilegiar determinado tipo de documento como forma de legitimar outro; e neste caso, a palavra escrita tende a se sobrepor às informações obtidas através do registro material ou oral, cada tipo de fonte apresenta uma relação de temporalidade e espacialidade diferente (Britton, 1997; Fuller, 1997; Kowalewki, 1997). Assim, as escalas de tempo utilizadas em análises de documentos escritos, de vestígios arqueológicos ou de relatos orais nem sempre são equivalentes. Feinman aponta, de uma maneira geral, uma estratégia para se fugir desses perigos, sendo, em primeiro lugar, o uso de multi-escalas temporais e espaciais, a partir das quais se pode trabalhar com escalas de micro e macro, interelacionando-as; em segundo, a realização de análises independentes para cada tipo de fonte, segundo critérios metodológicos particulares às mesmas, seguida de uma cuidadosa justaposição dos dados. O cruzamento desses dados propicia, desta maneira, uma base mais forte para as interpretações, evitando diminuir a importância de alguns dados e a supervalorização de outros.

Com a apresentação deste trabalho, procuramos abordar algumas destas questões em um estudo sobre a cultura material associada a africanos e afrodescendentes no Brasil escravista. Estudo este que apresenta uma dificuldade singular, pela natureza fragmentária dos indícios, sejam os materiais, documentais, iconográficos, orais, como é de se esperar, quando se trata de vestígios de personagens em posição subalterna em uma determinada comunidade ou sociedade. A fragmentação notada nesses indícios (e não apenas no vestígio arqueológico), já foi apontada por Young (1988), ao esclarecer como e porque a representatividade do registro documental e arqueológico deve ser considerada de forma equivalente, isto é, altamente fragmentário.

O estudo ao qual nos referimos se iniciou com a análise de amostras arqueológicas de cachimbos cerâmicos associadas a contextos do Rio de Janeiro, do século XIX, que estariam então associadas a escravos e ex-escravos, isto é, africanos e seus descendentes. Contudo, pela fragilidade dos contextos arqueológicos nos quais as amostras se inseriam, ou pela baixíssima frequência dessas peças em alguns sítios, partiu-se pa- 
ra um rastreamento mais amplo. Com isso, foram sistematicamente analisados cachimbos procedentes de 17 amostras arqueológicas e 2 museológicas, ${ }^{3}$ sendo a maior parte proveniente da região sudeste.

Os principais elementos que chamaram atenção na consulta e análise das peças foram a decoração, forma e técnica de confecção. Sendo estes os três elementos considerados na composição de estilos, fundamentados principalmente nos padrões de decoração. De uma maneira geral, detectou-se uma grande variedade de padróes decorativos, mas com a reprodução de alguns desses padrões, ${ }^{4}$ inclusive em regióes relativamente distantes, como é o caso de um dos padrões de maior incidência no Rio, que chega a ser encontrado em Porto Alegre; além da associação dos padrões a determinadas técnicas de confecção, como a modelagem ou o uso de moldes de duas partes. Um outro aspecto interessante é a relação que alguns desses padrões decorativos têm entre si, possibilitando observar transformações e/ou associações de determinadas manifestações estéticas. ${ }^{5}$

Se o mapeamento feito até o presente momento peca pela falta de uma análise contextual, que é justamente o limite da análise destas amostras, permite que pesquisadores com pequenas amostras deste material possam relacioná-las a uma recorrência mais ampla dos mesmos para uma determinada região, no caso, a região sudeste, especialmente o Rio de Janeiro. Apenas análises pontuais e contextualizadas proporcionarão interpretações mais refinadas acerca de seu uso e significado no passado.

Um fator que informa sobre a representatividade dos cachimbos como importantes suportes para a reprodução de padrões estilísticos, se apresentou quando, ao analisarmos algumas amostras de panelas reconhecidas como "neobrasileiras", e também contextualizadas no Rio de Janeiro do século XIX, ${ }^{6}$ cujos elementos decorativos são tradicionalmente associados à influência africana (Dias Jr., 1988), constatamos, ao contrário dos cachimbos, a ausência, ou uma baixíssima frequência, de reprodução dos motivos decorativos nas panelas, destacando aqui os motivos da decoração incisa. De fato, a extensão da análise das panelas não permite ainda maiores inferências sobre a representatividade destas frequências e a associação de padrões, mas nos oferecem indícios bastante sugestivos quanto à relevância dos cachimbos como suportes privilegiados para o estudo de escolhas conscientes de decoração de objetos de uso cotidiano e ritual.

Num primeiro momento da pesquisa sobre os cachimbos, foi levantada uma série de possibilidades para a interpretação da manifestação estilística presente nestas peças, sendo o comportamento étnico nosso foco central, uma vez que entendemos que determinados parâmetros estéticos poderiam ter se cristalizado nesses objetos, como mensagens que são materializadas e agem na formação e dinâmica de fronteiras étnicas (Agostini, 1998). Assim, cabe perguntar, independente do problema dos contextos arqueológicos, que limita o desenvolvimento dessa hipótese inicial, o que poderíamos dizer sobre estas manifestações estilísticas apresentadas pelo vestígio arqueológico acerca de seus significados e usos dentro de seu contexto sócio-cultural mais amplo?

Aqui entra o potencial dos estudos em Arqueologia Histórica quanto à disponibilidade de fontes de naturezas diversas, com diferentes tipos de informação a oferecer ao pesquisador. Assim, fontes escritas de natureza burocrática, documentação literária, iconografia, relatos orais e etnográficos, coleções museológicas e etnográficas, enfim, uma infinidade de possibilidades se abre para o desenvolvimento deste estudo. Contudo, é preciso observar algumas armadilhas no uso de informações provenientes de fontes diversas e estratégias para escapar delas no caso deste estudo.

As discussões sobre os problemas de análises que não consideram as diferentes escalas de tempo representadas pelas fontes utilizadas têm levado pesquisadores a definir quais problemas podem ser respondidos dentro de cada escala de tempo, e de que forma interelacionar as informações extraídas das diferentes fontes (Fuller, 1997; Kowalewski, 1997; Senatore, 1999). Na maior parte dos casos, ao tratar de escalas de tempo distintas, os autores se referem a escalas tão amplas a ponto de observar processos de mudança cultural na longa duração, englobando para isso vários séculos ou até mesmo um milênio por um lado, e, por outro, eventos e ações individuais, registros anuais ou mesmo circunstanciais. Desta maneira, importantes estudos vêm sendo desenvolvidos integrando dados trabalhados na curta e na longa duração. 
A estratégia para abordar a documentação escrita, iconográfica e material no caso deste estudo está, em primeiro lugar, em estabelecer critérios metodológicos de análise para cada fonte separadamente, através da construção de corpos de dados distintos, analisados sistematicamente. Considerando o contexto escolhido para o desenvolvimento de nossas questôes, esta construção possibilita enfocar as diferentes informações em uma escala de tempo semelhante, evitando a difícil tarefa de associar informações retiradas de eventos curtos ou histórias de vida a dados referentes a transformaçóes sociais e culturais observadas apenas com o passar dos séculos, abordando, para isso, algo que poderíamos chamar de "média duração". Este enfoque parece possível em virtude do contexto aqui trabalhado, que, diferente dos autores acima referidos, admite um recorte espaço-temporal semelhante para as diferentes fontes.

Isto parece possível quando consideramos, por exemplo, a faixa de um século, com alguns marcos importantes que podem definir uma variação no material empírico; e uma determinada região que tenha certo nível de homogeneidade no que tange à questão proposta. Assim, sugerimos tratamentos independentes para o material aqui trabalhado, isto é, as amostras arqueológicas, o corpo documental iconográfico, a série de processos criminais, e as listagens comerciais, mas sendo todos estes construídos e analisados dentro de uma visão espaço temporal relativamente equivalente.

Desta maneira, sugerimos analisar estes corpos documentais considerando o século XIX e a região sudeste brasileira como contexto mais amplo para se tratar da experiência de "africanos bantos" na reconstrução de identidades na diáspora. Pelo momento, em função das fontes já trabalhadas, nosso foco se centra especialmente no Rio de Janeiro oitocentista. Entende-se que tanto do ponto de vista arqueológico quanto histórico seja possível abordar a dinâmica da cultura material utilizada por esses personagens, considerando, neste contexto, marcos cronológicos importantes, como o ano de 1850, quando cessou o tráfico transatlântico de escravos, servindo assim como um divisor importante nas negociações identitárias entre africanos e seus descendentes. Um outro aspecto a se considerar, em termos espaciais, é a dinâmica e interação das zonas rurais e urbanas, especialmente no que tange ao fluxo de pessoas e circulação comercial de determinadas mercadorias, além de, é claro, as particularidades da vida dos escravos nas fazendas de café e na Corte.

Não será possível abordar de forma pormenorizada a construção de cada um desses corpos documentais, assunto para uma outra ocasião. Apenas apontaremos os cuidados e possibilidades observadas no tratamento de cada um desses corpos para inferir sobre a dinâmica e significados desses objetos. Assim, nos interessa extrair informações sobre a produção, circulação, aquisição, uso e significados conferidos a essas peças, tendo em vista a experiência e o comportamento de africanos e afrodescendentes na construção de novas identidades na diáspora, que podem ser encontradas, com perfis diferenciados, em cada uma das fontes analisadas.

Comecemos com algumas considerações sobre o tratamento de fontes com alto potencial qualitativo que podem informar sobre o contexto de uso da cultura material, e, com isso, seus possíveis significados: a iconografia de viajantes naturalistas e os testemunhos de diversos personagens que se manifestam em processos criminais.

Observando imagens produzidas por viajantes naturalistas no século XIX, podemos encontrar uma série de representaçōes de escravos fumando em cachimbos. Para trabalhá-las sugere-se aqui partir da elaboração de um índice temático (Leite, 1997). Em primeiro lugar, nota-se a incidência das representações e as circunstâncias nas quais negros aparecem fumando cachimbos. Pode-se observar cenas que acompanham todo o percurso de africanos recém-chegados ao Brasil, dos mercados no Porto do Rio de Janeiro, passando por ranchos no caminho para a zona rural, nas suas novas habitaçôes nas fazendas de café, retratando também seu uso em cenas cotidianas de trabalho ou associadas a momentos de descanso ou lazer, tanto em contextos rurais, quanto em contextos urbanos. Nenhuma cena ritual é retratada, mas algumas associações parecem sugestivas, como a escrava retratada por Debret que procura um vendedor de ervas, segurando um cachimbo sem que este esteja em uso. 
Além da indicação do uso de cachimbos ter sido amplamente disseminado entre os negros, ressaltando aqui que a maioria dos casos trata-se de mulheres, parece haver, em alguns casos, referência a este objeto como algo que atribui certa identidade a indivíduos, como a escrava retratada por Guillobel que carrega seu filho às costas, um cesto na cabeça e um enorme cachimbo na boca (Belluzzo, 1994: 91), ou do escravo retratado por Alken e Chamberlain, que, entre outros quatro na cena, é o único com roupas rasgadas e maltrapilho, caminhando tranquilamente com um grande cachimbo à boca (ibid., p. 94). Esta conotação de 'o escravo e seu cachimbo'7 também pode ser inferida em um outro registro imagético, como na fotografia feita por Henschel de uma negra de ganho ao lado de seus quitutes, posando como se estivesse fumando seu cachimbo (Alencastro, 1997: 61). Estas cenas devem, assim, ser entendidas como uma interpretação do olhar naturalista que cria e reproduz representações de personagens que circulavam à sua volta.

Um estudo de caráter quase etnográfico também pode ser feito a partir dessas imagens. Neste caso, contudo, é necessário um alto rigor metodológico, como mostrou Slenes ao analisar a obra de J.M.Rugendas (Slenes, 1995). Neste sentido, pode-se procurar observar o cuidado dos artistas na retratação de aspectos morfológicos dos cachimbos. Em alguns casos, observam-se grandes fornilhos, por vezes bastante rebuscados, como a referida escrava retratada por Guillobel e o escravo retratado por Alken e Chamberlain. Em outros, temos uma surpresa: formas muito semelhantes às formas dos cachimbos holandeses e ingleses de caulim ou gesso, embora majoritariamente retratados em tons de marrom, sugerindo serem de cerâmica. ${ }^{8}$ Em alguns casos chegam a ser retratados na cor branca, tais como os cachimbos europeus. ${ }^{9}$ A constatação imediata que se faz é que os negros estariam fazendo uso, além dos rústicos cachimbos de cerâmica, dos de caulim, de aquisição supostamente mais difícil para os cativos, e ainda reproduzindo a sua forma com o barro. Seguindo este raciocínio, seria possível concluir uma coerente análise de aculturação, onde os negros estariam, na medida do possível, buscando adquirir ou reproduzir os cachimbos dos brancos.

Se a iconografia de viajantes nos oferece possibilidades de inferências quase etnográficas sobre a cultura material, não nos poupa de armadilhas. Aqui fica clara a necessidade de uma análise específica para esta fonte, tão amplamente utilizada com fins de ilustrar discussões desenvolvidas a partir da documentação escrita. Tomemos como exemplo a prancha 'Uma banca do mercado' de Alken e Chamberlain (Belluzzo, 1994) na qual uma das negras é retratada fumando em um cachimbo idêntico aos cachimbos holandeses e ingleses de caulim. O primeiro cuidado a ser tomado na análise dessas imagens ${ }^{10}$ é saber a história da própria prancha em questão. Neste caso trata-se de uma cópia, isto é, o artista não presenciou necessariamente a cena e executou algum croqui no local, mas reproduziu uma pintura de J.C. Guillobel, executada em 1814. T. Ender executou outra cópia do mesmo original de Guillobel, em 1817 (Ferrez, s.d.). Nos três casos a mesma figura fumando o cachimbo é retratada, sendo que em cada caso a morfologia do cachimbo aparece de um jeito diferente. $\mathrm{O}$ original de Guillobel parece retratar uma forma simples e marrom. Na reprodução de Ender o cachimbo ainda parece ser de cerâmica (pela coloração escurecida), mas tem um fornilho mais proeminente, aparentemente decorado. Já no caso de Chamberlain, trata-se de uma peça fina e branca. É interessante que em outra pintura, Chamberlain, ao contrário da cópia feita a partir da pintura de Guillobel, faz questão de mostrar um grande e rebuscado cachimbo, cuja silhueta se pode acompanhar. ${ }^{11}$ Desta última, não temos informações que indiquem se tratar ou não de uma cópia.

Para prosseguir com esta análise seria necessário não só obter informações sobre datas e detalhes da produção de cada prancha, consultando croquis, mas da própria formação e prática artística desses naturalistas, trabalhando paralelamente a história da obra e a história do artista, para poder inferir sobre as concepções e informações empíricas que guiavam seus desenhos. Este cuidado pode trazer à luz informaçôes riquíssimas, como indica a sugestiva prancha 'Mercado de negros' de Rugendas (1989).

No caso desta pintura, apesar de apresentar no primeiro plano e ao centro um grupo de mulheres sentadas em torno de uma fogueira, estando uma delas a fumar um cachimbo, o que chama mais atenção é um detalhe do lado esquerdo, bem no canto, mas que pela técnica empregada pelo artista, julgamos ser um indício relevante. Trata-se do desenho realizado por dois escravos na parede do mercado, onde se pode ver o rosto de um homem, de traços alongados, com um fino bigode e algo semelhante a 
uma touca ou turbante na cabeça. Características de um dos motivos antropomorfos encontrados nos cachimbos das coleções arqueológicas (Agostini, 1997; 1998). A disposição do personagem branco, ao centro, que olha justamente em direção ao desenho, a abertura de um espaço na parede em que os escravos estão desenhando, deixando em evidência esta figura, e, ainda, o jogo de luz todo voltado na mesma direção, sugerem a consulta de originais (lembrando a possibilidade de alteração de detalhes em reproduções) para avaliar a precisão dos detalhes deste personagem, que pode ter sido reproduzido pelos negros em diferentes suportes; no caso desta cena, realizado por africanos recém-chegados do além-mar.

No caso de fontes como os processos criminais que envolvem escravos como vítimas, réus ou testemunhas, também é possível obter informações sobre o uso de cachimbos por africanos e seus descendentes no século XIX. A montagem de um índice temático, o estudo de redes e a chamada análise situacional apresentada por Van Velsen (1987) podem ser estratégias interessantes para análise desta documentação. A partir dos processos é possível vislumbrar fragmentos do cotidiano das pessoas interrogadas ou referidas, e, no que diz respeito aos cachimbos, é possível apontar alguns indícios de sua circulação, significado e uso entre os escravos.

No contexto rural do Rio de Janeiro, ${ }^{12}$ é possível observar no cotidiano da labuta escrava as brechas criadas pelos mesmos durante o serviço para obtenção de descanso. Essas situações frequentemente descrevem cativos que param o que estão fazendo, e, quando possível, se dirigem para um outro local para fumar seu cachimbo. Desta forma, este ato não só acaba por gerar conflitos com as forças de controle e dominação (especialmente feitores), como indica uma série de outros espaços "alternativos" para o encontro de negros, ${ }^{13}$ como foi o caso de uma escrava que "achando-se no quarto de costura, junto com sua parceira Ana e deu vontade de fumar, dirigiu-se para um rancho acender seu cachimbo; aí encontrou-se com Umbelino o qual pediu-lhe fogo e acendeu seu cigarro, agradecendo-lhe a espontaneidade (...)" ${ }^{14}$ No caso de cativos trabalhando na roça pode-se encontrar registros de escapadelas para as proximidades de um córrego, por exemplo, como foi o caso de Dario que deixou o serviço, e, sem aviso, “(...) foi para o lado de um córrego onde bebeu água e acendeu o cachimbo (...)". ${ }^{15}$

Uma outra informação acerca do uso de cachimbos por africanos e seus descendentes, escravos nas fazendas de café do Vale do Paraíba nos oitocentos, é a conotação de propriedade que tem essa peça, de forma que pessoas são identificadas pelas mesmas, como fez Agostinho, de Nação Moçambique, ao sugerir que seu parceiro Valentim era o responsável pela morte de uma pessoa, "(...) por ter sido achado perto do cadáver a bainha da faca e o cachimbo pertencente a Valentim (...)" ${ }^{16} \mathrm{O}$ empréstimo dos cachimbos parece também ter feito parte das negociaçóes cotidianas entre os cativos. O processo-crime no qual o escravo Adão foi suspeito e condenado descreve uma situação complicada, que envolve três escravos e dois cachimbos, na qual a justiça tenta entender quem emprestou o cachimbo a quem para poder acusar Adão, já que um dos cachimbos era uma evidência do crime. ${ }^{17}$

Neste caso, se a interpretação da situação é difícil, no contexto do processo, uma vez que possivelmente Adão estava dissimulando para tentar se livrar da culpa, ficou evidente que a possibilidade de empréstimo deste objeto entre parceiros era tão plausível quanto o caso do escravo Gabriel que emprestou sua faca a Jorge até poder pagar os 10 tostôes que lhe devia. ${ }^{18}$

Se os processos podem elucidar aspectos interessantes dos usos e significados desses objetos para africanos e afrodescendentes, também nos oferecem armadilhas. Uma das questôes levantadas a partir da análise dos vestígios arqueológicos, com implicaçôes importantes para o entendimento dos significados da reprodução de alguns padrões de decoração, foi justamente sobre as formas de aquisição dessas peças, sendo a sua manufatura individual e local ou em série e comercializada uma informação crucial para abordar a questão de etnicidade (Agostini, 1998). Neste sentido, um dos processos nos oferece uma informação tão interessante quanto perigosa: em um depoimento, o mencionado escravo Adão chega a se defender das acusações dizendo que "(...) quanto ao cachimbo novo, que Silvério apresentou, não é dele interrogado [Adão], mas sim comprado na freguesia (...) por dois vinténs, por ele interrogado emprestados a Silvério (...)". ${ }^{19}$ 
Neste caso é difícil avaliar o relato, uma vez que foi a única situação registrada de compra de cachimbo na vila, em toda a série dos processos; justamente numa circunstância em que Adão parecia estar dizendo, a todo o momento, qualquer coisa para livrar-se da acusação já tão bem formulada. Contudo, como já apontaram diversos autores que trabalharam com este tipo de documentação, o que importa não é se o que a testemunha diz é verdade, mas se ela usa o argumento, a exceçôes de situações esdrúxulas ou absurdas, é porque teria sido algo possível de ter acontecido (Chalhoub, 1998).

Assim, temos com essa informação dois indícios sugestivos. $\mathrm{O}$ primeiro, a possibilidade de venda de cachimbos nas vilas ou em mãos de mascates (por dois vinténs!), e, o segundo, a distinção que Adão faz do seu cachimbo com o outro, que foi comprado na vila, sugerindo que esta não foi a mesma fonte de aquisição do seu cachimbo. Neste caso, não é possível fazer maiores inferências, sem correr o risco de fazer uso de uma situação aleatoriamente para fins de comprovar ou responder uma questão levantada a partir do vestígio arqueológico.

Neste sentido, alerta-se que as perguntas possíveis de serem respondidas por cada tipo de fonte estão sim conectadas, e isto se dá por estarmos trabalhando em todos os casos com escalas de tempo semelhantes. Mas é absolutamente necessário, para manter o diálogo entre os diferentes corpos documentais, que a representatividade de cada informação seja averiguada com análises independentes, dentro do próprio grupo de documentos trabalhado, para que não haja riscos de se fazer uso das fontes para fins de comprovação ou ilustração.

Assim, partimos para uma terceira fonte histórica que nos oferece informações sobre esta circulação e produção dos cachimbos cerâmicos: as listagens de comércio. Ainda não foi levantada uma série documental que possibilite uma análise pormenorizada desta fonte, mas, ainda assim, podemos destacar algumas estratégias metodológicas que julgamos interessantes, e apresentar alguns indícios já levantados, a serem observados em pesquisas futuras.

Listagens de objetos vendidos em casas de comércio, secos e molhados, etc., assim como as que arrolam as mercadorias levadas por uma tropa ou navio, podem dar informações importantes a serem trabalhadas com as informações arqueológicas. Contudo, é necessário um estudo serial, para, mais uma vez, atestar a representatividade de cada informação. Formar uma série dessas listagens não é uma tarefa muito simples. Com uma lista de 208 nomes de donos de vendas, secos e molhados, tabernas etc., retirados de um alvará de licença para comércio em diversos locais da Província do Rio de Janeiro, ${ }^{20}$ foram encontrados apenas 22 inventários correspondentes a esses nomes, ${ }^{21}$ sendo que em apenas 1 deles encontrou-se as mercadorias existentes em sua casa de negócio. A dificuldade está em verificar se os nomes listados no alvará dizem respeito às mesmas pessoas que aparecem nos inventários, ou mesmo no fato de não terem os pequenos comerciantes - com os quais, supomos, os escravos fossem negociar grande posses, fazendo com que muitos não tivessem seus bens inventariados, dificultando a criação de uma série com os objetos e miudezas vendidos nesses estabelecimentos.

Para nossa felicidade, este único inventário encontrado entre os 208 nomes procurados, trata de objetos miúdos, entre os quais seguramente apareceriam cachimbos, se ali estivessem para vender. Pode-se assegurar isto uma vez que são discriminados objetos para fumo como charutos, cigarros e cigarros de palha, e nada de cachimbos. ${ }^{22}$ Nesse sentido, tanto neste caso, quanto no depoimento do escravo Adão que apresentam informações contraditórias - não é possível definir caminhos de inferência, uma vez que se tratam de fragmentos aleatórios, sem controles metodológicos que assegurem sua representatividade.

Uma lista de mercadorias importadas pela Corte de feitorias na África, referente ao ano de $1804,{ }^{23}$ nos mostra, mais uma vez, que determinadas informações são tão interessantes quanto perigosas. Nesta listagem pode-se encontrar a importação de 300 canudos para cachimbos, avaliados como ninharias (somando todos três mil réis) se comparados ao volume e valor de outras mercadorias importadas constantemente, como a cera (que para este mesmo ano chegou a somar mais de 95 contos de réis). 
Esta informação parece interessante em vários aspectos. O primeiro, é evidente: a importação de utensílios para cachimbos da África, quando estes podiam ser produzidos com facilidade em terras brasileiras. O segundo é que não são importados os cachimbos propriamente, mas os canudos, retratados tanto pela iconografia quanto pela literatura de viajantes que vieram ao Brasil e à África (Agostini, 1998) como muito longos.

É interessante notar a conformidade da informação obtida nesta lista com uma lacuna apresentada pelo registro arqueológico. Nem canudos nem moldes foram encontrados nos sítios arqueológicos dos quais são provenientes as amostras de cachimbos, sugerindo que os canudos eram de madeira e não teriam suportado as condiçóes pós-deposicionais; e que os sítios não eram os locais de produção das peças, pela ausência dos moldes. ${ }^{24}$ Esta conformidade pode levar o pesquisador a superar a lacuna da informação arqueológica com a informação obtida no registro escrito, indicando a importação de cachimbos da África. Contudo, este também é o caso de informaçôes obtidas de forma aleatória, sem um tratamento sistemático que apure sua representatividade como dado, ou, nas palavras de Mario Consens (2000), na construção de meta-dados. Contudo, se estas informações não podem ainda oferecer respostas, pela ausência de um tratamento sistematizado, oferecem indícios e com eles formulamos nossas hipóteses.

Desta maneira, se processos criminais informam sobre a relação entre usuários e objetos, as amostras arqueológicas nos indicam a circulação de padrões desses objetos em toda uma região e as preferências de consumo e/ou produção. Já a iconografia de viajantes, além de retratar imagens atribuídas a determinados personagens como usuários de cachimbos - representações -, pode nos oferecer informações quase etnográficas sobre as próprias peças. A informação oferecida pelas listagens comerciais também pode servir como uma luz sobre a produção e circulação dos cachimbos, repercutindo de forma decisiva nos possíveis significados atribuídos às manifestações estéticas que têm os cachimbos como suporte.

O objetivo aqui não foi esgotar as informações e possibilidades de interpretação dos dados até agora levantados, mas discutir sobre os perigos de análises que trabalham com fontes de diferentes naturezas, prática tão comum na arqueologia histórica, alertando para os cuidados ao cruzar informações que são, na verdade, apenas indícios; indicando estratégias para construção de dados, ressaltando como fundamental a realização desta construção de forma independente para cada corpo documental, para que seja feito, posteriormente, o cruzamento ou justaposição dos dados. Enfatiza-se também a necessidade do desenvolvimento de análises independentes para os diferentes tipos de fontes como forma de avaliar a representatividade da informação em seu contexto arqueológico e/ou documental, por um lado e, por outro, em seu contexto histórico mais amplo.

\section{Notas}

${ }^{1}$ v. especialmente Bintliff (1991); Knapp (1992); Archaeological Review from Cambridge. History and Archaeology, vol. 14 (1) 1997; Journal of Archaeological Method and Theory, vol. 4 (3/4) 1997, volumes dedicados ao uso de fontes históricas e arqueológicas em estudos com uma perspectiva holística.

${ }^{2}$ v. também Ravn (1997).

${ }^{3}$ Procedentes do RJ - 06 rurais, 02 semi-rurais, 01 urbano; de SP - 02 rurais, 02 urbano; de MG - 02 quilombos; ES - 01 urbano; PoA - 01 semirural; Museu - 02), tendo ainda consultado, sem desenvolver uma análise pormenorizada peças procedentes de Goiás, da Bahia, de Coleções etnográficas do Museu Nacional e do Museu da África Central (Tervuren / Bélgica).

${ }^{4}$ Das 19 amostras analisadas sistematicamente (somando um total de 128 cachimbos) pode-se notar cerca de 38 formas de decoração distintas, sendo que 11 aparecem repetidamente, formando padrões de decoração que representam c. 61\% da amostra total.

${ }^{5}$ Para uma análise pormenorizada dessas amostras v. Agostini (1997).

${ }^{6}$ As amostras são referentes aos seguintes sítios arqueológicos históricos: Fazenda da Mandioca, Solar Grandjean de Montigny e Imperial Sociedade Amante da Instrução, pesquisados ao longo das décadas de 1980 e 1990, no âmbito do projeto "Arqueologia Histórica no Rio de Janeiro: o século XIX”, coordenado pela Prof.a. Dr.a. Tania Andrade Lima.

${ }^{7}$ Conotação semelhante à atual imagem do 'preto velho' que está sempre acompanhado de um cachimbo. Isto é, a presença do cachimbo participa na definição / representação do personagem.

${ }^{8}$ v. e.g. prancha 'A Capoeira', de Rugendas (1989). 
CUlTURA MATERIAL E A EXPERIÊNCIA AFRICANA NO SUDESTE OITOCENTISTA: CACHIMBOS DE ESCRAVOS EM IMAGENS, HISTÓRIAS, ESTILOS E LISTAGENS

9 v. e.g. prancha 'O vendedor de ervas' de Debret (1993); 'Uma banca do mercado' de Clarke e Chamberlain (Belluzzo, 1994); 'O mercado de escravos'Alken e Chamberlain (Belluzzo, 1994).

${ }^{10}$ Para uma discussão pormenorizada sobre os cuidados a serem tomados na análise da obra dos viajantes v. Slenes (1988).

${ }^{11}$ Prancha 'Largo da Glória', de Alken e Chamberlain (Belluzzo, 1994).

${ }^{12}$ A circulação de cativos no contexto urbano do Rio de Janeiro e a relação com a prática do fumo em cachimbos já foi apresentada em artigo anterior (v. Agostini, 1998).

${ }^{13}$ Vale lembrar aqui, comparativamente, os ambientes em torno de fontes e chafarizes na Corte, descritos por Graham (1992) como locais de aglomeraçôes e encontro de negros.

${ }^{14}$ Processo-crime 082, Homicídio - 1879, p.22v. Centro de Documentação Histórica - Vassouras.

${ }^{15}$ Processo-crime 088, Homicício - 1844, p.31. Centro de Documentação Histórica - Vassouras.

${ }^{16}$ Processo-crime 045, Homicício - 1850, p.21. Centro de Documentação Histórica - Vassouras.

${ }^{17}$ Processo-crime 066, Homicício - 1866, p.23v. Centro de Documentação Histórica - Vassouras.

${ }^{18}$ Processo-crime 070, Homicício - 1867, p.18. Centro de Documentação Histórica - Vassouras.

${ }^{19}$ Processo-crime 066, Homicício - 1866, p.23v. Centro de Documentação Histórica - Vassouras.

${ }^{20}$ Arquivo Nacional, Alvará de licença para vários objetos - cód. 395, vol.1, 1823.

${ }^{21}$ Com a morte do proprietário de uma casa de negócio espera-se encontrar arrolados, em seu inventário, as mercadorias encontradas em seu estabelecimento, avaliando as posses do falecido.

${ }^{22}$ Arquivo Nacional, Inventário de João Alves da Silva - cx. 4147, n. 1533, 1850. Neste mesmo inventário também são arroladas panelas de barro, outro item consideravelmente difícil de encontrar nas listagens que arrolam mercadorias. A indicação de venda de panelas de barro é feita por Morales de los Rios (s.d., p.247), no final do XIX, que as cita entre os itens importados pela Corte da Bahia e de Santa Catarina.

${ }^{23}$ Biblioteca Nacional, Mapa das fazendas e gêneros importados na alfândega da cidade do Rio de Janeiro - I, 32, 14, 3, n.6, 1804. Agradeço a indicação deste documento pelo prof. Manolo G. Florentino (IFCH-UFRJ).

${ }^{24}$ Desconhecemos de que matéria-prima seriam feitos os moldes, mas pelos detalhes e dimensões das decorações em relevo nos cachimbos, dificilmente estes seriam de madeira.

\section{Referências bibliográficas}

AGOSTINI, Camilla. Cachimbos de escravos e a reconstrução de identidades africanas no Rio de Janeiro, século XIX. Monografia apresentada na obtenção do Bacharelado em Arqueologia da Universidade Estácio de Sá, Rio de Janeiro, 1997.

. Resistência cultural e reconstrução de identidades: um olhar sobre a cultura material de escravos do século XIX. Revista de História Regional, UEPG: Ponta Grossa, 1998.

ALENCASTRO, Luiz Felipe de. Vida privada e ordem privada no Império. In: NOVAIS, F.A. \& Alencastro, L.F. (ed.). História da vida privada no Brasil, Império: a corte e a modernidade nacional, vol. 2. São Paulo: Cia das Letras, 1997.

BELLUZZO, Ana Maria de M. A construção da paisagem. Coleção: O Brasil dos viajantes, vol. 3. São Paulo: Fundação Emílio Odebrecht, 1994.

BINTLIFF, John. The Annales School and Archaeology. London/New York: Leicester University Press, 1991.

BRITTON, Rupert. Stuck in the past: a historically oriented archaeology. Archaeological Review from Cambridge, vol. 14 (1), 1997.

CHALHOUB, Sidney. Visões da Liberdade. Uma história das últimas décadas da escravidão na corte. São Paulo: Cia das Letras, 1998.

CONSENS, Mario. Os milagres das taxonomias, ou a arte de fazer arqueologia. Anais da IX Reuniāo Cientifica sa Sociedade de Arqueologia Brasileira, Rio de Janeiro, 2000.

FEINMAN, Gary M. Thoughts on new approaches to Combining the archaeological and historical records. Journal of Archaeological Method and Theory, vol.4, n.os 3/4., 1997.

FERREZ, Gilberto. s.d. O velho Rio de Janeiro através das gravuras de Thomas Ender. São Paulo: Edições Melhoramentos.

FULLER, Dorian. The confluence of history and archaeology in lower Nubia: scales of continuity and change. Archaeological Review from Cambridge, vol. 14 (1), 1997. 
CUlTURA MATERIAL E A EXPERIÊNCIA AFRICANA NO SUDESTE OITOCENTISTA:

CACHIMBOS DE ESCRAVOS EM IMAGENS, HISTÓRIAS, ESTILOS E LISTAGENS

Camilla Agostini

GRAHAM, Sandra L. Proteção e obediência: criadas e seus patrōes no Rio de Janeiro, 1860-1910. São Paulo: Companhia das Letras, 1992.

HERSCHEND, Frands. Historical or textual archaeology: an archaeology of critical rereadind. Archaeological Review from Cambridge, vol. 14 (1), 1997.

KNAPP, A.B. Archaeology, Annales and Ethnohistory, New Directions in Archaeology. Cambridge: Cambridge University Press, 1992.

KOWALEWSKI, Stephen A. A spatial method for integrating data of different types. Archaeological Review from Cambridge, vol.14 (1).

LEITE, Miriam Lifchitz Moreira. Livros de Viagem. 1803-1900. Rio de Janeiro: Ed. UFRJ, 1997.

MORALES de los Rios, Adolfo, filho. (s.d.) O Rio de Janeiro Imperial. Ed. A Noite.

RUGENDAS, J.M. Viagem pitoresca através do Brasil. Coleção Reconquista do Brasil (3a série), vol. 8. Belo Horizonte: Ed. Itatiaia Limitada, 1989.

SENATORE, Maria Ximena. Arqueoloía del contato europeo-americano: discusión teórica y modelos de análisis en áreas marginales. Revista do Museu de Arqueologia e Etnologia. Suplemento 3, Anais da I Reunião Internacional de Teoria Arqueológica na América do Sul. São Paulo: USP, 1999.

SLENES, Robert W. Lares negros, olhares brancos: histórias da família escrava no século XIX. Revista Brasileira de História, 8: 16, 1988.

. Bávaros e Bakongo na 'habitação de negros': Johann Moritz Rugendas e a invenção do povo brasileiro. Trabalho em elaboração, mimeografado, versão 1995c.

YOUNG, T. Cuyler. Desde Heródoto, a história tem sido um conceito válido? American Antiquity 53 (1):7-12 (tradução não publicada por Irmhild Wüst / Universidade Federal de Goiás), 1988.

VAN VELSEN, J. A Análise Situacional e o método de estudo de caso detalhado. In: Feldman-Bianco, Bela. Antropologia das sociedades contemporâneas - Métodos. Global Universitária, 1987.

\section{RESUMO}

Este artigo aborda estratégias metodológicas no cruzamento de fontes de naturezas diferentes, considerando o uso de indícios e a construção de dados na produção acadêmica interdisciplinar. O interesse está em extrair informaçôes sobre a produção, circulação, aquisição, uso e significados conferidos a cachimbos, tendo em vista a experiência e o comportamento de africanos e afrodescendentes na diáspora. São trabalhadas fontes iconográficas, arqueológicas e escritas (processos-crime e listagens comerciais).

Palavras-chave: cultura material, africanos, região sudeste, Brasil, século XIX.

\section{ABSTRACT}

This article approaches the methodological strategies in the use of sources of different natures, considering the use of signs and the construction of data in the interdisciplinary academic production. The interest is to approach the production, circulation, acquisition, use and meaning given to pipes, considering the experience and behavior of Africans and Afro descendents of the Diaspora. The sources we work with are iconographic, archaeological and written (criminal processes and lists of goods).

Keywords: material culture, Africans, southeast Brazil, Nineteenth Century. 